Ana María Valencia Spoljaric y Maša Musulin Dol:10.4312/vh.27.1.231-248 Universidad de Zagreb

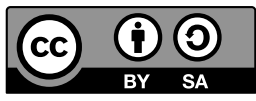

\title{
La mente multilingüe y la interferencia léxica
}

Palabras clave: transferencia léxica, interlengua, falsos cognados, adquisición de $\mathrm{L}_{3}$, español-croata

\section{Introducción}

El trabajo propone evaluar la transferencia de croata $\left(\mathrm{L}_{1}\right)$ y de inglés $\left(\mathrm{L}_{2}\right)$ que ocurre en la producción escrita del español como L3. En el sistema educativo croata, el inglés es la lengua extranjera que se introduce en el currículo ya desde la primaria. Según los datos de Eurostat $^{1}$ (2016), el 97,1 \% de los alumnos estudia inglés y el $95 \%$ estudia dos o más lenguas extranjeras. Estos números sitúan a Croacia en la cumbre de los países europeos en cuanto al tema de las LE. Según un informe de la Oficina Nacional de Estadística (2018)², 2357 estudiantes de secundaria y 247 de primaria estudiaban español en 2017. No tenemos datos exactos de las academias de lenguas extranjeras, pero conforme a ciertas estimaciones y proyecciones hechas a base de cuestionarios que rellenan los estudiantes de la Universidad de Zagreb al inscribirse en Filología Hispánica, un 22\% tomó clases de español en las academias de lenguas y no en la secundaria (principalmente por el motivo de que no en todas las escuelas se imparten clases de español).

El objetivo del presente trabajo fue indagar en qué medida interfieren las tres lenguas (croata como $\mathrm{L}_{1}$, inglés como $\mathrm{L}_{2}$ y español como $\mathrm{L}_{3}$ ) en el nivel léxico, debido a los frecuentes errores que se repiten año tras año en las clases de lengua. Los datos fueron recogidos de los ensayos que los estudiantes escribieron durante un cuatrimestre en la Universidad de Zagreb, en los primeros tres años

1 Para más información, véase el siguiente enlace: https://ec.europa.eu/eurostat/statistics-explained/index.php/Foreign_language_learning_statistics (15-06-2019)

2 Para más información, véase el siguiente enlace: https://www.dzs.hr/Hrv_Eng/publication/2018/08-01-03_01_2018.htm (17-06-2019) 
de grado de Filología Hispánica, lo que corresponde a los niveles de $\mathrm{A}_{2}$ a B2/C1 según el MCER. El análisis intenta clasificar los falsos cognados que aparecen como producto de una transferencia negativa, así como también analizar de qué idioma se están prestando los elementos lingüísticos y en qué medida. A la luz del hecho de que el previo conocimiento lingüístico juega un rol importante en el proceso de adquisición de las lenguas adicionales y que la mayoría de las similitudes entre las lenguas sucede precisamente en el nivel léxico, tratamos de ofrecer algunas implicaciones didácticas teniendo en cuenta la falta de investigaciones hechas entre el croata como lengua eslava y español como lengua romance.

\section{Transferencia léxica como producto del multilingüismo}

Odlin (1989: 27) define transferencia como «la influencia que resulta de las similitudes y diferencias entre la lengua meta y cualquier otra lengua que fue previamente (y quizás imperfectamente) adquirida». Al tratar de comprender cuándo ocurre la transferencia y en qué condiciones, se han formado tres posibles direcciones: (i) que la lengua más dominante (especialmente con los bilingües y hablantes de herencia) tendrá más influencia en la lengua meta (Montrul, 2008; Odlin, 1989), (ii) que la lengua con menos restricciones lingüísticas influye en la lengua con más restricciones (Hulk y Müller, 2000) y (iii) que todas las lenguas ya adquiridas mutuamente influyen una en otra y en la producción léxica (De Angelis y Selinker, 2001).

Para entender mejor la mente del aprendiz a la hora de adquirir dos o más lenguas, cabe definir dos términos que a menudo irrumpen en relación a los procesos cognitivos y que llevan a varias interferencias, las cuales vamos a elaborar. Moreno García (2010: 120) distingue como dos conceptos diferentes el multilingüismo, como «el conocimiento de varias lenguas o la coexistencia de distintas lenguas en una sociedad determinada», y el plurilingüismo, «como las variedades lingüísticas que utiliza un mismo locutor incluyendo la materna como primera y las posteriormente adquiridas».

Por otro lado, el MCER (2002) destaca que el estudiante crea sus propios enlaces interlingüísticos e interculturales entre las lenguas que ya conoce, lo que, por un lado, le facilita el aprendizaje en el caso de una transferencia positiva de su L1 o de otras lenguas. Por otro lado, es importante desarrollar la conciencia lingüística, o más bien conciencia sobre las lenguas 3 , para poder

3 Martín Peris (2014: 57) entiende la conciencia sobre las lenguas como «una conciencia sobre fenómenos concretos de las distintas lenguas que componen el repertorio lingüístico del aprendiz». 
diferir entre los grados de transferencia y para poder controlar las transferencias negativas, especialmente a nivel morfosintáctico y léxico. Todavía carecemos de los criterios suficientes para definir los grados de plurilingüismo, por lo cual unos autores (Jelaska, 2003; Pavličević-Franić, 2011) difieren entre el plurilingüismo horizontal, que representa la relación entre la lengua materna y diferentes lenguas extranjeras, y el plurilingüismo vertical, como la relación diglósica entre diferentes idiomas orgánicos de una lengua con la lengua estándar.

La adquisición de la lengua extranjera es un proceso complejo que subyace en el conocimiento previo de las lenguas ya aprendidas. Como resultado de este fenómeno, surgen lenguas e interlenguas con su propia complejidad. La influencia interlingüística se observa fácilmente en el nivel léxico, que también es la clase más frecuente de transferencia, y sucede porque el sistema de la lengua meta todavía no está completa o suficientemente adquirido. La transferencia positiva igual puede darse especialmente entre las lenguas de la misma familia, donde el estudiante puede percibir las similitudes (ciertas lenguas eslavas entre sí, lenguas romances, etc.). Como este trabajo se centra en tres lenguas de varias familias (eslava, germánica y romance), se analizarán las siguientes clases de transferencia: falsos cognados totales y parciales -como producto de la interferencia semántica-e invenciones léxicas -como productos de la transferencia morfológica-, especialmente los casos donde por influencia de los sufijos de la $L_{1}$ o L2, se añaden sufijos españoles que forman una nueva palabra no apropiada.

\section{Falsos amigos en la adquisición de L3}

Los falsos amigos son dos palabras que son iguales o similares en su pronunciación o en su forma escrita, pero su significado es diferente. También aparecen bajo los nombres falsos cognados, falsos pares, palabras engañosas, en su mayoría a partir de algunas traducciones de otros idiomas (Broz, 2008: 200). Como no existe una tipología estandarizada y generalmente aceptada, mencionaremos ciertas distinciones que existen entre autores. Chacón Beltrán (2006) distingue entre los falsos cognados parciales y totales, pero también diferencia entre los cognados fonéticos y gráficos, refiriéndose al hecho de si la forma de pronunciar o de escribir se parece. Chamizo-Domínguez (2008) distingue entre los falsos amigos semánticos, que pueden ser totales y parciales, destacando también que la similitud puede emerger de su parecido fonético o gráfico, y falsos amigos por casualidad -el término que él mismo 
acuñó-, cuyo significado no coincide por no tener el mismo origen etimológico. Ringbom (2007: 73) destaca que son usualmente las lenguas relacionadas, pero a veces igual las no relacionadas, las que comparten cierto número de cognados, y distingue entre «los históricamente relacionados, vocablos similares por forma, cuyo significado puede ser idéntico, similar, parcialmente diferente o de vez en cuando aun completamente diferente», y los divide en dos grupos: por transferencia de forma y de significado, es decir, los cognados pueden ser totales o parciales fijándose más que nada en la forma del vocablo. En el presente trabajo decidimos adoptar esta última división, y aunque al final se tomará en cuenta el significado de la palabra, queríamos hacer diferencia entre el aspecto morfológico y semántico, precisamente porque habíamos notado las invenciones nuevas donde se une la raíz de la $\mathrm{L}_{2}$ con la desinencia de la $\mathrm{L}_{3}$ o al revés (cro. papirologija, esp. papirología en vez de papeleo), por lo cual tales palabras las categorizamos como cambio de forma. En cuanto al aspecto semántico, nos quedamos con la división usada por la mayoría, la de falsos cognados parciales y totales, donde nos basamos en la similitud de los vocablos que acarrea una confusión en el momento de elegir el significado y el uso correcto.

\section{$4 \quad$ Análisis}

Al principio del cuatrismestre del año académico 2018-2019, los estudiantes de los tres años de grado de Filología Hispánica de la Universidad de Zagreb rellenaron un cuestionario que nos proveyó de los biodatos sobre su educación en referencia a las lenguas extranjeras. Ofrecemos a continuación los datos más significativos: los 35 estudiantes del primer curso declaran el croata como su L1, salvo una estudiante que es bilingüe y que como $\mathrm{L}_{1}$ tiene el croata y portugués. Todos los estudiantes como L2 tienen el inglés, salvo uno que indicó alemán. El $61 \%$ de los estudiantes (22) especifican que el español es su L3 y para el resto, su L4. En el segundo año, de los 25 estudiantes todos ponen croata como $\mathrm{L}_{1}$, salvo una estudiante que es bilingüe y como $\mathrm{L}_{1}$ tiene también el polaco. De nuevo, todos los estudiantes poseen como L2 el inglés, solo uno el alemán. Aquí un $51 \%$ tiene el español como L 3 y el resto como L4. En el tercer año de los 23 estudiantes el 100\% afirma que el croata es su L1, y 21 estudiantes mencionan que el inglés es su L2, mientras que dos estudiantes optan por el noruego y español como su segunda lengua. De ellos el $49 \%$ pone el español como $\mathrm{L}_{3}$ y el resto como $\mathrm{L}_{4}$. Hemos separado las redacciones de los estudiantes que no tienen inglés como $\mathrm{L}_{2}$, mientras que entre el $\mathrm{L}_{3}$ y $\mathrm{L}_{4}$ 
no hicimos diferencia, especialmente porque hoy en día generalmente la adquisición de la tercera lengua se refiere a las lenguas aprendidas después de la segunda, es decir, a «la adquisición de las lenguas no nativas por los aprendices que previamente han adquirido o están adquiriendo dos diferentes lenguas» (Cenoz, 2003: 71).

\subsection{Muestra recogida}

Como mencionamos anteriormente, las muestras han sido extraídas de 316 ensayos (4 por estudiante) que los estudiantes del primer, segundo y tercer curso de los estudios de grado en Lengua y Literaturas Hispánicas han redactado en el último cuatrimestre de estudios. En total, hemos hallado una incidencia de 53 falsos cognados en dichas redacciones.

Para facilitar su análisis, la muestra recogida ha sido dividida en dos grandes grupos. El primero, en referencia a la interferencia en el aspecto morfológico, introduce aquellos falsos cognados que guardan una similitud de forma entre la lengua materna -croata-, o la L2 -inglés-, con la lengua meta -español-. Como consecuencia, nos hallamos con dos términos parecidos en español, pero los estudiantes optan por uno por la influencia de su par en la L1 o L2. La interferencia o bien radica en un sufijo calcado del croata o del inglés en vez de presentar el apropiado en español, o bien se mantiene el lexema de la lengua materna o L2. Asimismo, en la división también se incluirá de qué lengua proviene la interferencia.

El segundo grupo gira en torno a la interferencia en el aspecto semántico; en este caso, la forma de las lenguas aprendidas previamente se corresponde con un vocablo en español, mas el significado global o uno de ellos no encaja. Por ello, dividiremos estos falsos amigos en totales -aquellos en que sus acepciones no se corresponden en absoluto- y parciales -aquellos en que una o más de las acepciones sí coinciden, pero una (o más) en particular no-. Nuevamente en cada caso se especificará si la interferencia proviene del croata o del inglés.

Hemos tomado como base para las definiciones tres diccionarios que son los más representativos y usados en cada lengua. En el caso del español, recurrimos al Diccionario de la lengua española (en adelante: $D L E$ ), una obra representativa no solo de la Real Academia Española, sino también de las Academias de los países donde se habla español, por lo que es el referente para la lengua española. En cuanto al croata, las consultas se han hecho al Hrvatski jezični 
portal (en adelante: $H J P^{4}$ ), que es el diccionario de la lengua croata más usado en internet, y para el inglés, se eligió el diccionario Collins English Dictionary (en adelante: Collins); nos decantamos por la variante del inglés británico, ya que en la mayoría de las escuelas croatas los manuales que utilizan los estudiantes introducen dicha variante, por lo que están más familiarizados con el inglés británico. Tanto el DLE como el Collins han sido consultados en sus versiones online.

A continuación, presentaremos las tablas con las muestras obtenidas, divididas según lo explicado anteriormente. Para el análisis, solo nos enfocaremos en aquellos vocablos que presentan una mayor incidencia entre los estudiantes.

\subsection{Falsos amigos: aspecto morfológico}

En la Tabla 1 y Tabla 2 podemos apreciar dos pares en español, cuyas formas guardan similitud, pero cuyos significados varían. Como mencionamos anteriormente, el estudiante se decanta por uno de ellos al reproducir el sufijo o el lexema de la L1 o L2. A continuación, empezaremos analizando los vocablos cuya influencia proviene del croata.

\begin{tabular}{|c|c|c|}
\hline \multicolumn{2}{|c|}{ Falsos cognados } & \multirow[b]{2}{*}{ Vocablo correcto en español } \\
\hline En español & En croata & \\
\hline 1. Documentario & Dokumentarac & Documental \\
\hline 2. $\quad$ Mórbido & Morbidan & Morboso \\
\hline 3. Promover & Promovirati & Promocionar \\
\hline 4. Populación & Populacija & Población \\
\hline 5. Papirología & Papirologija & Papeleo \\
\hline 6. Consumación & Konzumacija & Consumo \\
\hline
\end{tabular}

Tabla 1. Aspecto morfológico, interferencia del croata

En el primer ejemplo nos encontramos con los pares documentario y documental. En la siguiente oración escrita por un estudiante del segundo curso, (1) A veces bay documentarios y buenas películas, también se emiten series, notamos que incurre en un error al suponer, por influencia del croata, dokumentarac -suposición reforzada por el vocablo en inglés documentary-, que el sufijo adecuado en español sería -ario, por ello la forma documentario. En el DLE, documentario se

4 El diccionario HJP (Portal de la lengua croata) fue formado a base de varios diccionarios de la lengua croata publicados en papel en los últimos 15 años por la casa editorial de Zagreb Novi Liber. 
define como 'Que se funda en documentos reales' y bajo esa acepción también puede usarse documental. Por lo tanto, ambas palabras son falsos amigos parciales, ya que comparten solo una acepción, pero la que nos compete, 'Dicho de una película cinematográfica o de un programa televisivo: Que representa, con carácter informativo o didáctico, hechos, escenas, experimentos, etc., tomados de la realidad', solo la posee documental.

Otro caso de interferencia del sufijo de la L1 es la palabra mórbido; por influencia del croata morbidan -y del inglés morbid-, el estudiante agrega el sufijo -ido para mantener la $-d$ al crear un derivado de la palabra morbo. Sin embargo, mórbido significa o '1. Que padece enfermedad o la ocasiona' o '2. Blando, delicado, suave', y en la oración (2) Es mórbido ver programas que muestran las desgracias bumanas, debió usarse morboso, cuya tercera acepción es 'Que provoca reacciones mentales moralmente insanas o que es resultado de ellas'.

Por otro lado, un ejemplo de calco del lexema lo encontramos en populación. En (3) Sabemos que la populación con mayores problemas de salud es la populación de Eslavonia, podemos notar que incurren en error al suponer que en este caso se debe conservar el lexema del croata populacija, lo que da como resultado populación. Observamos que también esta elección se ve reforzada por el inglés, population. Además, ambas formas comparten el sufijo -cro. -acija, ing. -ation-. Sin embargo, populación es 'Acción y efecto de poblar', acepción compartida con población. Así, nuevamente populación y población son falsos amigos parciales, debido a que comparten solo una acepción, pero la que se refiere a 'Conjunto de personas que habitan en un determinado lugar', que es la que se necesita en el ejemplo (3), solo la posee población en su segunda acepción.

Otro caso es la palabra consumación. En (4) La consumación de productos nocivos sube al igual que las enfermedades crónicas, por influencia del croata -konzumacija-, el estudiante repite el lexema konzum, así como el sufijo -acija, en español -ación. El problema radica en que consumación deriva del verbo consumar, no de consumir. Por lo tanto, su significado es '2. Extinción, acabamiento total', o '1. Acción y efecto de consumar'. El verbo consumar tiene tres acepciones: '1. Llevar a cabo totalmente algo', '2. Dicho de los legítimamente casados: Revalidar el matrimonio realizando el primer acto sexual en cumplimiento del débito conyugal', '3. Ejecutar o dar cumplimiento a un contrato o a otro acto jurídico', pero ninguna de ellas posee el significado de 'ingerir'. El sustantivo que se necesita en la oración (4) es consumo, derivado del verbo consumir, que en su segunda acepción significa 'Utilizar comestibles u otros bienes para satisfacer necesidades o deseos'. 
En la Tabla 2, encontramos los vocablos cuya interferencia en el aspecto morfológico provienen del inglés.

\begin{tabular}{|l|l|l|}
\hline \multicolumn{2}{|c|}{ Falsos cognados } & \multirow{2}{*}{ Vocablo correcto en español } \\
\hline En español & En inglés & Temporal \\
\hline 7. $\quad$ Temporario & Temporary & Expectativa \\
\hline 8. $\quad$ Expectación & Expectation & Representantes \\
\hline 9. $\quad$ Representativos & Representatives & Conservador \\
\hline 10. Conservativo & Conservative & Significativo \\
\hline 11. Significante & Significant & Invertir \\
\hline 12. Investir & To invest & Sostenible \\
\hline 13. Sustentable & Sustainable & Respeto \\
\hline 14. Respecto & Respect & Apariencia \\
\hline 15. Aparición & Appereance & \\
\hline
\end{tabular}

Tabla 2. Aspecto morfológico, interferencia del inglés

Detallaremos cuatro ejemplos en cuya derivación los estudiantes recurrieron a la forma del sufijo en inglés. En (5) No dejan ninguna buella significante, el estudiante adoptó la forma del inglés significant, que significa 'importante' o 'notable'. Sin embargo, significante es '1. Que significa' o '2. Ling. Fonema o secuencia de fonemas que, asociados con un significado, constituyen un signo lingüístico'. En la oración (5) se necesita el significado de 'Que tiene importancia por representar o significar algo' que lo proporciona el vocablo significativo, con el sufijo -ativo.

Otro ejemplo son los vocablos conservativo y conservador. En (6) Como nuestra sociedad es muy conservativa, no es extraño que comentaran esa película, la palabra conservativo copia el sufijo -ivo del inglés conservative, que hace referencia a 'una persona tradicional'. En español conservativo es 'Que conserva algo', valor con el que también cuenta conservador, pero este último vocablo en su segunda acepción posee el significado de 'En política, especialmente favorable a mantener el orden social y los valores tradicionales frente a las innovaciones y los cambios radicales' o en su tercera acepción, 'Tradicional', que es el adecuado para la oración (6).

En (7) Eso puede causar algunos problemas porque no tenemos expectaciones, el vocablo expectación calca la forma del inglés expectation, ambos con sufijos -ación y -ation. Expectación significa en su primera acepción 'Espera, generalmente curiosa o tensa, de un acontecimiento que interesa o importa', mientras que 
expectativa, con el sufijo -iva, en su primera acepción significa 'Esperanza de realizar o conseguir algo'. El vocablo inglés contiene ambas acepciones, de ahí la equivocación.

Entre los errores de calco del lexema, destaca investir. En (8) Es mejor investir en la prevención, el estudiante transfiere el lexema del inglés invest. En español, investir es solo 'Conferir una dignidad o cargo importante'. El vocablo adecuado para el ejemplo (8) sería invertir, en su segunda acepción significa 'Emplear, gastar, colocar un caudal'. Invest en inglés abarca ambos significados, tanto de investir como de invertir, en su primera y tercera acepción.

\subsection{Aspecto semántico}

\subsubsection{Falsos amigos totales}

En la Tabla 3 y Tabla 4 observaremos una lista de falsos cognados cuya interferencia se basa en que la forma de los vocablos provenientes de la L1 o L2 guarda una gran similitud con la forma de una palabra en español; por lo tanto, el significado también es transferido. Sin embargo, en español correspondería otro vocablo diferente.

Empezaremos analizando la muestra cuya interferencia proviene del croata.

\begin{tabular}{|l|l|l|}
\hline \multicolumn{2}{|c|}{ Falsos cognados } & \multirow{2}{*}{ Vocablo correcto en español } \\
\hline En español & En croata & Minucioso, meticuloso \\
\hline 16. Pedante & Pedantan & Competencia, oponente \\
\hline 17. Concurrencia & Konkurencija & Ubicación \\
\hline 18. Locación & Locacija & Escuela secundaria, liceo \\
\hline 19. Gimnasia & Gimnazija & Delicia \\
\hline 20. Delicadeza & Delikatesa & \\
\hline
\end{tabular}

Tabla 3. Aspecto semántico - falsos amigos totales, interferencia del croata

Analicemos el caso de la palabra pedante. En (9) Muchos dicen que los alemanes son severos y reservados, incluso son pedantes y sus babilidades de organización son impresionantes, el vocablo deriva de la palabra croata pedantan. En español pedante se refiere a 'Dicho de una persona: Engreída y que hace inoportuno y vano alarde de erudición, téngala o no en realidad'. El término adecuado en español sería meticuloso 'Dicho de una persona: Muy escrupulosa y concienzuda en sus acciones', significado que coincide con la primera acepción de pedantan en croata. 
Otra palabra que con frecuencia los estudiantes entremezclan es gimnasia. En (10) Las escuelas secundarias se dividen por el plan de estudios en gimnasias, escuelas vocacionales y escuelas artísticas, el error en el uso de gimnasia deriva de la palabra croata gimnazija que solo significa 'un tipo de escuela secundaria'. Sin embargo, gimnasia en español quiere decir ' 1 . Actividad destinada a desarrollar, fortalecer y mantener en buen estado físico el cuerpo por medio de una serie de ejercicios y movimientos reglados'. Es decir, se refiere a una actividad física. El término adecuado sería escuela secundaria o liceo.

Otro vocablo que suelen confundir es locación. En (11) Juan escucbó un coche acercándose a su locación, el uso de ese término proviene de la influencia de lokacija, palabra croata que significa 'lugar' o 'ubicación'. Este uso viene corroborado por la palabra inglesa location. En español según el DLE, locación significa solo 'arrendamiento' y se utiliza en el ámbito del derecho. La influencia es tan grande que la Fundación del Español Urgente (Fundéu) remarca que «el uso de locación como equivalente de localización es un calco semántico del vocablo inglés location [...]. Es innecesario su empleo, pues en español existen otras voces con las que se puede expresar la idea de localización; por ejemplo, localidad, lugar, ciudad, país, sede, etcétera»5.

Por otro lado, también hemos obtenido muestras de falsos amigos totales, pero cuya interferencia proviene del inglés, los cuales se pueden apreciar en la Tabla 4 .

\begin{tabular}{|l|l|l|}
\hline \multicolumn{2}{|c|}{ Falsos cognados } & \multirow{2}{*}{ Vocablo correcto en español } \\
\hline En español & En inglés & Concursante \\
\hline 21. Contestadora & Contestant & Darse cuenta de \\
\hline 22. Realizar & To realize & Notas \\
\hline 23. Grados & Grades & Con formación \\
\hline 24. Educado & Educated & \\
\hline
\end{tabular}

Tabla 4. Aspecto semántico - falsos amigos totales, interferencia del inglés

Pasaremos a analizar tres vocablos: realizar, grados y educado. En (12) Cuando oí cómo era su vida, realicé qué fácil mi niñez era, observamos una interferencia del inglés to realize que en su primera acepción significa 'darse cuenta de algo', significado que los estudiantes trasladan al español. Sin embargo, realizar en ninguna de sus cuatro acepciones denota el significado de 'darse

5 Véase: https://www.fundeu.es/noticia/la-esquina-del-idioma-locacion-no-significa-lugarsitio-pais-4466/ 
cuenta de' o 'ser consciente de', locuciones que se deberían haber utilizado en el ejemplo (12).

El segundo ejemplo recurrente es grado. En (13) Mi abuela nunca era una alumna excelente, pero tampoco tenía grados malos. La influencia para la elección de dicho vocablo proviene del inglés, grades. La palabra grado en español en ninguna de las diecisiete acepciones que posee presenta el significado de 'nota', que es el vocablo que se debería usar en la oración (13).

En tercer lugar, nos encontramos con la palabra educado. En (14) El cortometraje muestra la dura realidad que atraviesan algunos inmigrantes, sobre todo los que no son muy educados, el estudiante elige el vocablo educado por interferencia del inglés educated, que hace referencia en su primera acepción a 'tener estudios o formación'. El uso de educado es erróneo porque significa 'Que tiene buena educación o urbanidad', no necesariamente títulos o diplomas.

\subsubsection{Falsos amigos parciales}

En el siguiente apartado detallaremos los vocablos que son falsos cognados parciales, es decir, que sí existen algunas acepciones de la L1 o L2 que coinciden con el español, pero otras no, y es allí donde se genera la equivocación. Pasaremos a explicar en primer lugar los falsos amigos parciales cuya interferencia nace por una acepción errónea extraída del croata.

\begin{tabular}{|l|l|l|}
\hline \multicolumn{2}{|c|}{ Falsos amigos } & \\
\hline En español & En croata & Vocablo correcto en español \\
\hline 25. Programa & Program & Canal \\
\hline 26. Término & Termin & Cita \\
\hline 27. Cualidades & Kvaliteta & Calidades \\
\hline 28. Ambulante & Ambulanta & Consultorio \\
\hline 29. Escenario & Scenarij & Guion \\
\hline 30. Y & I & También \\
\hline 31. Colisión & Kolizija & Cruce de clases \\
\hline 32. Americano & Amerikanac & Estadounidense \\
\hline 33. Mascarar & Maskirati se & Poner una máscara/disfraz \\
\hline
\end{tabular}

Tabla 5. Falsos amigos parciales - interferencia del croata

Uno de los vocablos que los estudiantes suelen utilizar reiteradamente en forma equivocada es programa. En el ejemplo (15) En el programa Nova TV 
bay un show que se llama Farma, hallamos una interferencia de la palabra croata program; ambos vocablos existen tanto en español como en croata, coinciden en algunas acepciones ('Distribución de las materias de un curso' o 'Instrucciones de una computadora'), pero aquella que es la adecuada para la oración (15) solo existe en croata; en español el vocablo adecuado sería canal (de televisión).

Las palabras escenario y scenarij comparten una forma similar en ambas lenguas, así como ciertas acepciones (reforzada por la palabra inglesa scenario), pero hay una que suele crear interferencias en los estudiantes. En (16) El escenario de la película está muy bien escrito y ganó varios premios, la palabra escenario se usa por influencia de scenarij que en croata en su primera acepción significa 'guion', término que se debería utilizar en español.

En (17) Además de la pérdida de comida, la Tomatina significa y una gran pérdida de agua, la conjunción y está erróneamente usada por la influencia de la $i$ en croata, cuya tercera acepción tiene el significado de 'intensificar, añadir', que la y en español no cuenta. Por ello, en la oración debió utilizarse otro vocablo para intensificar la repetición, como el adverbio también, por ejemplo.

En este acápite pasaremos a detallar algunos ejemplos de falsos amigos parciales cuya interferencia deriva de la L2, los cuales podemos apreciar en la Tabla 6.

\begin{tabular}{|l|l|l|}
\hline \multicolumn{2}{|c|}{ Falsos amigos } & \multicolumn{1}{l}{ Vocablo correcto en español } \\
\hline En español & En inglés & Mudarse \\
\hline 34. Moverse & To move & Familiares \\
\hline 35. Relativos & Relatives & Tener éxito \\
\hline 36. Suceder & To succeed & Prestar atención, escuchar \\
\hline 37. Atender la clase & To attend & Presentar a alguien \\
\hline 38. Introducir a alguien & To introduce & Ayudar o mantener \\
\hline 39. Soportar a alguien & To support & Discusión \\
\hline 40. Argumento & Argument & Dar como resultado \\
\hline 41. Resultar & To result & Local \\
\hline 42. Doméstico & Domestic & Quedarse, descansar \\
\hline 43. Restar & To rest & Límite, frontera \\
\hline 44. Borde & Border & Personaje \\
\hline 45. Carácter & Character & Cartas \\
\hline 46. Letras & Letters & Asignatura o tema \\
\hline 47. Sujeto & Subject & Postular \\
\hline 48. Aplicar /aplicación & To apply & Sospechar \\
\hline 49. Sospechoso & Suspicious & \\
\hline
\end{tabular}




\begin{tabular}{|l|l|l|}
\hline \multicolumn{2}{|c|}{ Falsos amigos } \\
\hline En español & En inglés & Vocablo correcto en español \\
\hline 50. Facto & Fact & Hecho \\
\hline 51. Exhibición & Exhibition & Exposición \\
\hline 52. Anciano & Ancient & Antiguo \\
\hline 53. Sumar & To sum up & Resumir \\
\hline
\end{tabular}

Tabla 6. Falsos amigos parciales - interferencia del inglés

Empezaremos con el vocablo moverse. En el ejemplo (18) Ella es originaria de Koprivnica, pero se babia movido cuando era estudiantes, al vocablo moverse le ha sido impuesta la segunda acepción de su par en inglés, to move, que se refiere a 'cambiar de vivienda o lugar de trabajo'. Sin embargo, el vocablo en español no cuenta con esa definición. La palabra adecuada sería mudarse.

En (19) Sabe, don Juan, mis padres murieron en un accidente y como no tuvimos ningunos relativos ni familia, la policía decidió mandarme a una casa donde viven niños sin padres, la palabra relativo, similar tanto en inglés como en español, posee algunas acepciones en común, pero la adecuada para el ejemplo solo la posee su par en inglés, relatives, en su novena acepción. En el caso del español la palabra apropiada sería familiar o pariente.

En (20) Mi carácter favorito es Gonzalo Infante, la palabra carácter está usada erróneamente. Si bien es cierto que carácter y character comparten ciertas acepciones, la de 'personaje' no la posee la palabra en español. Para ello, habría que utilizar personaje o protagonista, si fuera el personaje principal.

En (21) En la galería babía una exbibición de pinturas modernas, notamos una interferencia del inglés, exbibition. Sin embargo, exbibición en español, no se refiere a 'presentar obras de arte', para ello contamos con la palabra exposición. Es interesante mencionar que en croata también se hace la diferencia entre ekshibicija, como en español, 'mostrar alguna destreza' e izložba, 'exposición'. No obstante, observamos que el vocablo en inglés predomina.

Otro falso cognado nace de la asociación de letra en español y letter en inglés, que guardan algunas acepciones en común ('signos gráficos de un alfabeto' o 'pieza de la imprenta'). En (22) Mi abuelo y mi padre solían escribir las letras y yo solamente escribi dos letras en mi vida, la interferencia nace por la segunda acepción que contiene letter, la de 'comunicación escrita', que en español, letra también lo comparte, pero está en desuso, como lo aclara el DLE, por lo que no se aconseja su uso. Debió escribirse carta. 
En la oración (23) Tengo que soportar a mis amigos cuando tienen problemas, hallamos el verbo soportar usado por la influencia de su par en inglés to support. Si bien es cierto que ambos verbos guardan acepciones en común como 'Sostener sobre sí un peso' o 'Tolerar o llevar con paciencia', en la oración destaca la sexta acepción de to support, que en español recaen en los verbos apoyar o ayudar, los cuales debieron utilizarse en la oración (23).

\section{Conclusión}

Como previamente hemos mencionado, los estudiantes en la mayoría de los casos, recurren al inglés en el momento de producir nuevas invenciones léxicas o en el caso de los falsos cognados. De los 59 ejemplos encontrados, unos 20 provienen del croata y el resto del inglés. Ello fue lo esperado, ya que la $\mathrm{L}_{1}$ y $\mathrm{L}_{3}$ en nuestro caso no están relacionadas (una por ser lengua eslava, y la otra, lengua romance), por lo cual "es natural para los aprendices buscar las similitudes léxicas y estructurales entre L2 y L3" (Ringbom, 2007: 78), en nuestro caso el inglés. En los ejemplos de cambio morfológico, en la mayoría de los casos se ha mostrado que los estudiantes optan por un sufijo español influencia por la $\mathrm{L}_{1} \mathrm{o} \mathrm{L}_{2}-$, con lo cual la palabra les suena más familiar, más española (documentario, papirología...). En cuanto a los ejemplos semánticos, se trata de los típicos ejemplos de falsos amigos donde se usa el significado no apropiado, aunque de nuevo mucho más con el material lingüístico de L2, en este caso inglés. Comparando los ejemplos obtenidos en el nivel morfológico y el semántico, también se puede concluir que hay más transferencia negativa en el nivel semántico, lo que atribuimos al hecho de que este efecto ocurre donde todavía no se ha desarrollado una adquisición completa, aunque los estudiantes del tercer curso tienen ciertas competencias del nivel $\mathrm{B}_{2}-\mathrm{C}_{1}$ según el $M C E R$, por lo cual la producción basada solo en la similitud de forma inevitablemente lleva a un uso inadecuado. Por lo tanto, el presente trabajo también puede servir como guía para los profesores de ELE, cuyos estudiantes tengan como lengua materna el croata y como LE inglés, con el fin de que puedan identificar con qué vocablos hallamos las mayores incidencias de falsos cognados y por qué sucede esta interferencia y de esta manera facilitar la adquisición apropiada del léxico del español. Asimismo, cabe señalar que se trata de una investigación que se encuentra en desarrollo, por lo cual todas las informaciones obtenidas se utilizarán en futuros análisis, especialmente por ser conscientes de la carencia de trabajos centrados en el español y las lenguas eslavas, y aún menos el croata. 


\section{Bibliografía}

Broz, V. (2008): «Diachronic Investigations of False Friends». Suvremena lingvistika, 66, 199-222.

Cenoz, J. (2003): «The additive effect of bilinguism on third language acquisition: A review». International Journal of Bilinguism, 7, 71-88.

Chacón Beltrán, M. R. (2006): «Towards a typological classification of false friends (Spanish English)». Revista española de lingüistica aplicada, 19, 29-40.

Chamizo Domínguez, P. J. (2008): Semantics and Pragmatics of False Friends. New York/London: Routledge.

Collins Cobuild Active English Dictionary (2018 $\left.8^{13}\right)$. London, Collins Cobuild: https://www.collinsdictionary.com/ (10-06-2019)

Consejo de Europa (2002): Marco común europeo de referencia para las lenguas: aprendizaje, enseñanza y evaluación (MCER). Madrid: Secretaría General Técnica del MECD-Subdirección General de Información y Publicaciones, y Grupo ANAYA, S. A.

De Angelis, G., Selinker, L. (2001): «Interlanguage Transfer and Competing Linguistic Systems in the Multilingual Mind». En: Jazone Cenoz, Britta Hufeisen, Ulrike Jessner (Eds.), Cross-Linguistic Influence in Third Language Acquisition: Psycholinguistic Perspectives. Clevedon: Multilingual Matters, $42-58$.

Fundación del Español Urgente (Fundéu): https://www.fundeu.es/ (13-06-2019)

Gabryś-Barker, D. (2005): Aspect of multilingual storage, processing and retrieval. Katowice: University of Silesia Press.

Hrvatski jezični portal: http://hjp.noviliber.hr/ (09-06-2019)

Hulk, A., Müller, N. (2000): «Bilingual first language acquisition at the interface between syntax and pragmatics». Bilingualism: Language and Cognition, 3(3), 227-244.

Jelaska, Z. (2003): «Hrvatski jezik i višejezičnost». En: Melita Kovačević, Dunja Pavličević Franić (Eds.), Kompetencija u višejezičnoj sredini II, 106126. Jastrebarsko: Naklada Slap.

Martín Peris, E. (2014): «Un modelo de enfoque plurilingüe para la enseñanza de lenguas en la escuela». Linguarum Arena, Vol 5, 47-66.

Moreno García, María Esther (2010): «El plurilingüismo como necesidad en la sociedad actual». Pedagogía magna, 8, 120-126. 
Montrul, S. (2008): «Incomplete acquisition in Spanish heritage speakers: Chronological age or interface vulnerabilitiy?». En: Harvey Chan, Heather Jacob, Enkeleida Kapia (eds.), Proceedings of the 32nd Annual Boston University Conference on Language Development. Somerville, MA: Cascadilla Press, 299-310.

Odlin, T. (1989): Language transfer: Crosslinguistic influence in language learning. Cambridge: Cambridge University Press.

Pavličević-Franić, D. (2011): Jezikopisnice - rasprave o usvajanju, učenju $i$ poučavanju brvatskoga jezika u ranojezičnome diskursu. Zagreb: Alfa.

Real Academia Española (2001 $\left.{ }^{23}\right)$ : Diccionario de la lengua española. Madrid: Espasa-Calpe: https://dle.rae.es/ (10-06-2019)

Ringbom, H. (2007): Cross-linguistic Similarity in Foreign Language Learning. Clevedon: Multilingual Matters Ltd. 


\section{Ana María Valencia Spoljaric and Maša Musulin} University of Zagreb

\section{Multilingual mind and lexical interference}

Keywords: lexical interference, crosslinguistic data, deceptive cognates, acquisition of $\mathrm{L}_{3}$, Spanish-Croatian

The student creates his own interlinguistic and intercultural links between the languages he already knows, and this is especially strong at the initial level. One of the objectives of this study is to explain the role played by previous languages in the learning of a target language, and also in what situations they influence the learning process of the target language and how (De Angelis, 2007; Ringbom, 2007). Therefore, the work proposes to evaluate the transfer in written production of Spanish by students whose mother tongue is Croatian and whose $\mathrm{L}_{2}$ is English. The objective is to investigate to what extent the three languages are interlaced (Croatian, L1, English, L2, Spanish, L3) at the lexical level. The data was compiled from the essays that the Spanish students of the University of Zagreb wrote during one semester. The analysis attempts to classify the errors that occur, establish how the cognates behave, what language they borrow from and to what extent. 
Ana María Valencia Spoljaric in Maša Musulin Univerza v Zagrebu

\section{Večjezični um in leksikalna interferenca}

Ključne besede: leksikalna transferenca, vmesni jezik, lažni prijatelji, usvajanje tretjega jezika, španščina-hrvaščina

Študenti ustvarjajo lastne medjezikovne in medkulturne povezave med jeziki, ki jih že poznajo, kar je še posebej pomenljivo na začetni stopnji. V pričujočem prispevku se namerava med drugim razložiti vlogo prej naučenih jezikov pri učenju ciljnega jezika ter tudi v kakšnih okoliščinah in kako vplivajo na proces učenja ciljnega jezika (De Angelis in Selinker, 2007; Ringbom, 2007). Avtorici se tako namenita ovrednotiti transferenco pri študentih, katerih materni jezik je hrvaščina, drugi pa angleščina, pri pisnem izražanju v španskem jeziku. Namen prispevka je namreč raziskati, v kolikšni meri se ti trije jeziki (hrvaščina kot prvi, angleščina kot drugi in španščina kot tretji jezik) prepletajo na ravni besedišča. Podatki so zbrani na osnovi esejev, ki so jih študenti španščine $z$ Univerze v Zagrebu napisali v enem semestru študijskega leta 2018-2019. V analizi se skuša razvrstiti zaznane napake, opredeliti vedenje lažnih prijateljev in določiti, iz katerega jezika izvirajo in v kolikšni meri. 